\title{
The Right of Children to Use Cultural Heritage as a Cultural Right
}

\author{
Antonella Nuzzaci \\ Department of Human Studies, University of L'Aquila, L'Aquila, Italy \\ Email: antonella.nuzzaci@univaq.it
}

How to cite this paper: Nuzzaci, A. (2020). The Right of Children to Use Cultural Heritage as a Cultural Right. Open Journal of Social Sciences, 8, 574-599.

https://doi.org/10.4236/jss.2020.84042

Received: March 20, 2020

Accepted: April 27, 2020

Published: April 30, 2020

Copyright $\odot 2020$ by author(s) and Scientific Research Publishing Inc. This work is licensed under the Creative Commons Attribution International License (CC BY 4.0).

http://creativecommons.org/licenses/by/4.0/

\begin{abstract}
The contribution analyzes the children's right to use the cultural heritage, in all its forms, and it shows how it is a cultural right aimed at strengthening children's skills profiles and raising the quality of education. It focuses on the idea that denial of this right is nothing but the other side of the coin of social and cultural exclusion. The goal of the contribution is to highlight the reflections produced following a series of empirical research conducted by the author in the Italian and international fields focused on the relationship between literacy, multiliteracies and cultural and museum use. The idea of cultural heritage as tangible and intangible signs of culture and as bearers of its symbolic systems leads us to speculate how their failure to use specific categories of individuals only makes cultural gaps stronger and nourishes new forms of exclusion. The right to fruition is in fact still closely connected to the robustness of the profile of skills and socio-economic variables, which can be said to be the indicator of profound inequalities. Even today, in fact, the use of cultural heritage is adopted as an indicator of the cultural status of a certain population. This leads to reasoning on how important it is, from a very young age, to enable each individual to consciously enjoy cultural goods, so that various inequalities do not increase and culture should no longer serve to console men in sufferings, but to protect them from them, fight them and eliminate them. The contribution analyzes these issues by trying to capture the interrelationships between culture, cultural heritage and education in reference to the rights and quality of education.
\end{abstract}

\section{Keywords}

Cultural Rights, Use of Cultural Goods, Cultural Heritage, Quality of Education, Enjoyment Cultural Goods

\section{Introduction}

The expression "cultural heritage" has not taken on the same meaning over time. 
It has seen both the term heritage and that of culture change. Therefore, the concept of cultural heritage (artistic, historical, archaeological etc.), such as that of cultural heritage, has gradually come to include new categories, for example, industrial archeology. A considerable effort was then made to extend this concept also to the intangible inheritance by introducing the distinction between materiality and immateriality. Attention is now being paid to other cultural forms such as dramatic arts, languages, traditional music or information systems etc., which shows that the idea of heritage does not cease to expand its boundaries and meanings by assuming an almost unlimited extension.

Cultural heritage is therefore an open concept today, as it is now evident that culture is a dynamic process, which reflects every component of life in the present and in the past. In all its aspects, it affirms in a tangible way that every man, every group or social practice is also a cultural outcome. So a table is the effect of a cultural evolution as is a Rachmaninov sonata, a Molière comedy, a Racine tragedy or Picasso's Guernica. This phenomenon is the result of another, more profound phenomenon, which concerns the way in which the different communities understand and represent each other.

Culture is therefore constantly evolving and depends largely on the interpretations that its representatives give; it can be said, in fact, the ability that allows to constantly and precisely extend the range of perceptions of its meanings (Dewey, 1916/2000). Moving from one phase to another, it adopts new cultural practices and abandons others that have survived up to that moment, but that have generated the new ones and that are essential to make it relevant to the process of change. The continuous precarious balance in which culture lives therefore also extends its interpretative scope by modifying its ability to adapt to changes.

There is therefore a relationship between social practices and the construction of identities (Levi-Strauss, 1980), which have many relationships with history, heritage, culture, language and awareness, as well as having a complex of different characteristics and futures. In this sense, personal identity and society are complementary elements in the construction of reality (Mead, 1934/1966). Identity does not belong exclusively to the individual but is understood as a structure of a social order whose construction is the result of a self-regulatory process that relates the representations of oneself and those of reality itself. Consequently, the continuous practices of human beings in the context of groups, by means of which the participants build the character and identity of a community and the specific patterns of behaviors that differentiate one community from all the others, lead to conceive the culture essentially as a construct that describes the total body of beliefs, behaviors, knowledge, sanctions, values and objectives, which distinguish the way people live: what they have, do and think (Herskovitz, 1948: p. 625).

However, the "possession" of culture requires the owner to be aware of his "knowledge", who in order to truly "master" it not only must have some idea of it, but also live it and be consciously "imbued" with it.

Generally, however, a person of culture is someone who can speak languages 
other than his own, who is familiar with history, literature, geography, etc., who in short has mastered a certain number of knowledge and abilities. In reality, the cultured man is not someone who knows many things or who has a smattering of everything, but the one who is able to intervene on himself and on culture by grasping the problems and intervening on it to modify it. Those who learn to solve problems, identify their limits and remedy them participate in culture because this is one of its creations and is made to be communicated and supported by precise cultural codes (Bruner, 1988).

Past experience of oneself and of other human beings, in the form of culture, comes into play in almost every event of existence. Each specific culture provides a sort of trace for all the activities of life (Kluckonhn, 1960). In this sense, it includes not only the set of knowledge of the individual, but also the intellectual heritage of a people and is an integral and active part in the processes of sustainable development, also economic. It represents a formidable resource for the improvement of the material and spiritual living conditions of countries and men. The need therefore arises to think differently about the elements of heritage, which is increasingly defined as historically transmitted bodies of meaning and situations within a network of relationships within which men's actions become "cultural facts". Precisely in culture, understood as the context of production and interpretation of meanings, spaces open up between a great variety of cultural, social and artistic forms that include both object and non-object goods. It is clear then that culture is not a genre and that instead all genres are cultural treatises (Parascandolo, 1997: p. 162).

With respect to this plurality of culture, which continuously diversifies and constantly changes its forms, as well as progressively differentiates the methods of fruition, talking about education to the "good" becomes essential to understand the multiplicity of transformations taking place in this culture today.

The contribution first of all addresses the relationship between culture, cultural heritage and education, paying particular attention to promoting the right to cultural enjoyment, to the processes of cultural democratization and learning of cultural heritage, which are the basis of active citizenship, equality and equity. The following paragraphs mark this interpretative path.

\section{Relationship between Culture, Cultural Heritage and Education}

What relationship exists between culture, cultural heritage, children's rights and education?

If education is basically a triple process whereby the child becomes an adult, the member of a society and culture at a certain time and in a particular place, a subject with a personal history, then the cultural good pushes education forward to make it a real movement of socialization and individuality at the same time, which allows the individual to enter the specificity of the symbolic universes, to access specific cultures, to build the self and one's identity.

Drawing some implications from the foregoing, we could recognize that her- 
itage education is a right to the root, it is a right to the future, but it is also a universal right, a right to cultural difference and personal originality. In short, this is a right to be taken into consideration when we speak of "cultural pluralism", within which the universality of human rights and the individual's education in children's rights are realized. This dynamic set of rights is necessary to counterbalance the exaggerated organization and excessive control of adults over the lives of children which imply a narrow perception of culture and not on the contrary a large dimension of it.

It is an observation that cannot leave us indifferent, especially when we think about the fact that adults often involve children in educational and social conflicts that are difficult to deal with and that the educational process is not such as to enable the child to witness the discoveries of culture, instead often resolving itself in a process marked by authoritarianism.

But obedience is not a virtue, wrote Don Milani (1965), who, in order to guarantee access to culture for all, pointed his finger at the disparity of the starting points, on the claim of culture to be above the parts, on the impossibility of ignoring the social conditions and the recognition of the cultures of which the subjects who would like to acculturate are bearers. This is something similar to what is observed today in the fight against "illiteratism", or functional illiteracy, with which it must be noted that the way of relating to reality is filtered by alphabetical culture. Obviously, this does not mean that alphabetic skills should be used exclusively in professional life, but it is appropriate that they should instead be considered necessary also to benefit from the material and immaterial heritage (literature, art, science, etc.) available to the community. For our purposes, however, it is important to consider the right to literacy and that of fruition as variously representable phenomena that influence each other.

Over the last few years there has been a slow expansion of the social base of use over time. However, the emergence of a broader fruition did not in reality correspond to a change in the cultural profile of the population, which sees the latter manifesting regressive tendencies regarding the possession of the same basic alphabetic skills that should guarantee subjects the appropriation of the repertoire symbolic elements they need to benefit from experience with the cultural heritage.

It follows that, if there is no education in culture and cultural heritage, that is, an education that gets used to cultural responsibility, choice, dialogue, understanding, etc., "fundamental education" is also missing (UNESCO, 1949) and, with it, something of that basic justice that all countries are committed to promoting is also missing. The expression "basic education" is now obsolete, but it was used in the mid-1940s to describe a particular level or sector of educational systems, that is, indicating an education that would allow the acquisition of reading and writing skills and other skills essential, as well as the knowledge and values necessary to participate in society (pp. 11-12). And what we now call "literacy" or perhaps it would be better to use the term "multiliteracies", that is 
what is culturally necessary and can only be common.

With this concept, with which, at first, the emphasis was placed on the "needs and urgent problems" of the communities, the international community then proposed itself, through compulsory primary, "elementary" and "fundamental", education, to "meet everyone's basic learning needs". If, however, since then basic education has been progressively interpreted as "functional literacy", in the sense of progressive "satisfaction" with individual learning needs, then the fact that the community itself then opened the question on how it appears to be decisive needs must be interpreted and fulfilled. The World Declaration on Education for allof Jomtien (United Nations, 1990) went in this direction which, in addition to recognizing the importance of early childhood for the subsequent development of the child, also addressed, among others, the problem of expanding the means and aims of basic education arguing not only that "knowing how to read and write in the mother tongue strengthens identity and cultural heritage", but also that all "the tools and channels of information available, communications and social action must be used to contribute to transmit essential knowledge and to inform and educate".

In addition to traditional means, therefore, "new" (and at the same time old) means, such as museums for example, should be used by schools in such a way as to constitute a complementary "integrated system" capable of reinforcing the basic cultural profiles of the population and helping school systems to better meet the demand for education. From an operational point of view, in terms of "means and methods" of implementation, the recognition of the importance of cultural heritage for the development of the child brings with it a new way of addressing the issue of literacy, widely interpreted as education for the community. This opens up more promising, and certainly better outlined, avenues for education, which make it possible to identify and respond in an increasingly appropriate manner to the difficulties faced by different social groups in resolving conflicts concerning the possession of the complex and functional symbolic repertoire indispensable for the individual to "act" in reality (Figure 1).

The presence or absence of a substantial symbolic repertoire in fact configures a new way of dealing with the problems of fruition, of understanding and formulating messages and of learning to learn, linking them to the phenomena of globalization (Schmidt, 2000), but which still do not appear all solved by the school system. Due to its characteristics, the cultural asset seems to guarantee a better appropriation of the symbolic repertoire by interacting with other significant variables of the educational path (Nuzzaci, 2001; 2007; 2015). Perception and use of heritage would modify and increase, through the processes of elaboration and understanding of the messages that the good transmits, different types of learning (Nuzzaci, 2001; 2004a; 2004b; 2017).

More precisely, a monument, an object, an image and so on are symbols, whose understanding helps the individual to take part in the system of regulation of society by means of which social consensus is achieved, the ideal collection (cohesive power ): therefore they have enormous value for the community. 


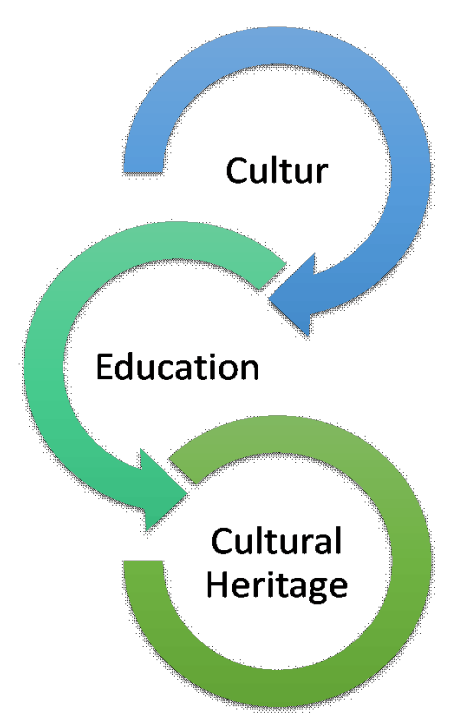

Figure 1. Interrelations between culture, education and cultural heritage.

This social balance symbolically binds men together and encompasses the idealization of wanting to live together, the symbolic representation of the common good and forges the national identity. Heritage then appears as a symbolic construction of unity and social diversity, in which men's aspirations and desires are reflected and crystallized.

As a mirror and expression of man's uses, beliefs, values, attitudes and behaviors of man, the good in itself is an "integrated model of knowledge" capable of affecting the quality of the training measures implemented in educational institutions (Nuzzaci, 2016). It is in fact through its understanding that children can grasp the complexity and richness of the meanings of the context in which they live, capturing the variety, continuity and relationships that are defined in it.

But to get to decode and interpret the cultural messages of which the "good" is the bearer, one cannot ignore the knowledge of the elements, codes and the fundamental lexicon it uses to exist, in particular:

- constituents, that is, the great configurations of meaning that are proper to them (figures, circumstances, events, etc.), sufficiently distinct and circumscribable in relation to other elements;

- syntax, that is, of the reciprocal connection of the constituents (the relationships that each element establishes with respect to the others and in the spatial and temporal whole).

Languages and symbolic tools that are acquired naturally starting from a solid basic literacy that can allow all this, as established by the "Convention on the Rights of the Child", which, in article 31, establishes the right of the child to participate freely to cultural and artistic life. This is a dilation of the concept of the child's right to culture, which obviously implies the extension of the right to education, which in turn encompasses both the right of children to be educated and the process of building the "shared" identity cultural between children and adults. 
This means that the child has the right to enjoy culture in all its expressions, manifestations and possible modalities and that education is responsible for encouraging its development while respecting each one's particularities and diversity. Cultural heritage is therefore an indispensable element of knowledge capable of positively qualifying learning: it is a real "social construction" which provides the basis for more dynamic family, school, etc. interactions.

It is like saying that the stimuli deriving from the use of cultural heritage produce evident relationship effects on social behavior. Moreover, it is precisely within the cultural contexts that the processes of interpretation of reality are generated, which take place through the discourses, objects and interactions proper to a community. Culture is reflected within us and is expressed in relations with parents, children, relatives, friends and strangers as well as in the relationship with other cultures and with the physical world; it can be said to be the heart of training, education and ethics and it is what gives man a paramount importance in relation to other disciplines (Galisson \& Puren, 1999: p. 114).

\section{Promoting the Right to Cultural Enjoyment}

The starting point of a speech that sees the right of children to enjoy heritage within a broader framework of cultural rights is well expressed by the Preamble of the European Constitution, which sees individuals "united in diversity", inspired by to the cultural, religious and humanistic legacies of Europe, from which the universal values of the inviolable and inalienable rights of the person, freedom, democracy, equality, and the rule of law have developed (European Constitution, 29 October 2004).

This is the starting point of a speech that sees the right of children to enjoy the heritage within a broader framework of cultural rights, as well expressed by the Preamble of the European Constitution: Within these coordinates, the right of the child to take part fully in community life is respected and promoted and "the organization, in conditions of equality, of appropriate means of entertainment and recreational, artistic and cultural activities" is encouraged (Convention on children's rights). Here we move in an educational perspective that invites us to go beyond reading the good as a sign of the existing and that rather pushes us to grasp new educational horizons and strategies capable of promoting a free, participatory, critical and responsible fruition. We can hope for all this only under the pressure of a great effort of society aimed at research, discovery and development and governed not only by scientific curiosity but also and above all by tenacity and civil courage.

Let us now make more explicit the transition between the right to education and the right to cultural enjoyment. In our opinion, the link is given by the right of children to equality, equal opportunities, a right often overlooked or contained in others and whose strengthening prevents the implementation of new strategies of cultural discrimination. Although the relationship between education and heritage has changed at the same time as social changes, there is still no 
denying the crucial role that culture plays in creating barriers, in delimiting borders, in legitimizing the exclusion of marginalized groups, in reproducing inequalities.

If therefore we do not want heritage to act as an instrument of social exclusion (Sandell, 1998: p. 410) in terms of access, participation and representation, it is important that it plays an active role in the path of cultural appropriation by ceasing to be dominion and expression of an elite, a distinctive element of belonging to socially favored classes and therefore an instrument of demarcation between those who are included in certain processes and those who remain excluded.

It now seems clear to us, at this point, how the realization of the right to use the heritage necessarily passes through the educational process, whose main task is to make children learn what the world is and not instead to inculcate them art of living (Arendt, 1961/2001: pp. 242-255). As Philippe Meirieu (2002), well states, the only truth about the rights of the child is that of the right to be educated, to receive an education that only adults can give him. Although many scholars converge on the fact that such education should prepare children for exercising citizenship, there is no agreement on the conditions of this preparation and on the very nature of the proposed education. It is right and useful to ask then what are the indispensable components of a so-called "basic" culture.

Surely it refers to those central competences that define a strong cultural profile, which ensures possession of a wide interpretative repertoire and has a high degree of symbolic elements and tools, which put the individual in a position to decode and organize the multiplicity of messages with which he comes into contact. There is no doubt that accepting the argument that we have exposed about the importance of skills acquired through cultural means entails seeing the claim that the "human right to education" is a central value and requires that adults take responsibility for building training contexts capable of guaranteeing the child's right to be and grow.

Since every child represents the becoming of humanity, as we often hear repeated, in order for this "tomorrow" to be positively realized it is essential to give life to a school capable of fully expressing the right to education, indispensable for the evolution of culture and democracy. In other words, school education determines the maximum use when one of its contents becomes the plurality of codes through which social communication is defined; and this is precisely what allows it to create authentic conditions of choice that allow the individual to operate freely and to continuously reread the goods of the past through the gaze of the present.

By its very nature, the school is the institution that mediates entry into culture. When the children enter, their acculturation process within the family has already begun. Consequently if it is true that the school does not exhaust all the sources and ways of learning (Pontecorvo, Ajello, \& Zucchermaglio, 1995) it is equally true that it represents the place where a mediated experience takes place, 
that is, an experience which uses the means and symbols of culture.

The school is the foundation for the development of cultural society and in it the different forms of expression (art, music etc.) become basic literacy together with "writing, reading and accounting", together with the use of technologies and possession of a second or third community language. But above all it is the place where you learn to use culture to solve problems and questions, because doubting, questioning, investigating, are values that are more necessary than ever today in a society in which we live of perhaps exaggeratedly unique thinking and too generalized consent.

All contemporary pedagogy, starting with John Dewey (1961), underlined the centrality of the doubt in the learning process, which, starting from the questions, is adequately supported by the adult only when it allows the child to follow a road guided by intuitions, discoveries, reflections that will not be forgotten. In fact, it is almost obvious that we will never forget the things we learn with passion. This discourse pushes us to make another consideration: the cognitive and affective fallout of the experience with the cultural good will have positive effects and will be appreciable for those who do it only if motivating and if "constructively" inserted in the complexity of the training path.

If this is significant in a perspective of development of educational progress, it should nevertheless be borne in mind that children's participation in culture is guaranteed by two conditions: the richness of the experience and the in-depth understanding of it. At present, there does not seem to be information available that shows whether access and participation in education are fully satisfactory and there are few accessible international indicators capable of monitoring progress towards this goal.

In this perspective, "education in cultural heritage" can only evoke an idea of globalized culture for all and for all, regardless of age or social and cultural status, and therefore cannot be reduced to a domain of reserved knowledge or to a "noble form of entertainment". Instead, there is still a division of the population between those who have a high degree of symbolic tools and those who do not have them. These are two companies: the first exercises a substantial hegemony, since the conservation and increase of the living conditions of the other society, which is majority and structurally subordinate, depends on it.

The reasons for these inequalities are complex and certainly have to do with the wealth and power of different social groups. The use of heritage is considered a sort of "index" that somehow registers those who have come out of "marginality" and are able to participate in the processes of social and cultural transformation. Learning to benefit from the good, for ever higher portions of the population, therefore amounts to laying the foundations for bringing out minorities and pulling them out of a historical-cultural subjugation. Nonetheless, culture means, also and above all, "conscious consumption", sharing a cognitive heritage, of which a certain repertoire of basic skills, not least linguistic ones, is a decisive part. This creates a first real form of capitalization of knowledge. 
All this means that the barriers that hinder learning do not fall on their own but instead it is necessary to understand what kind they are in order to implement specific actions suitable to overcome them. It follows that reflection is crucial for learning cultural heritage because it can help develop the necessary self-awareness and see the problems and things to change.

For these reasons, understanding cultural heritage can only mean grafting the experience of the good onto an adequate interpretative repertoire and strong skills capable of promoting the acquisition of precise methods of knowledge and the promotion of attitudes and behaviours suitable to face the problems concerning heritage education (Nuzzaci, 2016), which helps the child to build himself as a cultural subject that structures his own conduct by organizing his cultural experiences. This construction will be the more effective if knowledge in the "cultural space" will be well promoted. This means making children learn culture/cultures, discovering their traces, documents, objects, and conceptualizing their rules, regularities, characteristics, components.

"Teaching culture" requires "cultural mastery" and basically reveals an essential and substantial question, that is, the status and role of the school in the training of man and citizen (European Commission, 2018). It is for this reason that educational actions must be promoted to help the child

- become aware of the heritage (learn and master the principles according to which the heritage is organized and used);

- use it;

- work on the attitude towards fruition (which implies the ability to use the learning opportunities offered by the conditions of the heritage);

- appeal to different personal and cultural resources to understand it.

This vision underlies the conception that the child, as well as the adult, can be fully competent in matters of culture and democracy.

If we dwell better on the idea that culture is also a phenomenon given by our state of knowledge and that of the group then we must inevitably assert that all children have the right to possess this culture and to preserve their identity, which includes a name, a nationality and a cultural heritage in fact, but which requires, at the same time, to be continually rethought in a dialogical relationship between diachronic reconstruction and projection towards the future. From this point of view every "everyone has the right freely to participate in the cultural life of the community, to enjoy the arts and to share in scientific advancement and its benefits" (United, Nations, Universal Declaration of Human Rights, 1948, Art. 27).

In this way, the use and learning of the cultural property support the children's right to be and exist in history, in the present and in the future with greater force. Cultural heritage also means children's heritage, only that children's signs are often considered non-existent elements of cultural heritage; and this violates the recognition of the child's right to identity and learning, an acknowledgment which instead constitutes an important challenge for humanity today. Giving 
voice to childhood therefore means, also on this level, accrediting children of their right to be users and authors of goods. Giving the floor to children allows, in a more concrete dimension, to redefine concepts that seemed acquired and to ask what are the systems of signs that underlie the activities of "reading" the goods themselves, which being located in the sphere of the symbolic play a strong role of socialization, that is, they become a yardstick for assessing and recognizing social belonging. But it is also necessary to ask what image of culture and cultural heritage children are formed in order not to risk that childhood is resolved, also on this level, as a terrain for the projection of the wishes of adults.

What has been said leads us to explore issues related to equality, socio-cultural heritage, but also to cultural participation, education, integration and social classes as well as to the analysis of the processes of inclusion and exclusion of individuals and social strata in a given community context.

In this way, we move from the general debate on heritage education to a typically social dimension of it, in which the real reasons for this discourse emerge, which still see cultural opportunity as an opportunity that benefits those who are already socially favored.

Generally, art and culture are considered aspects that are part of separate moments of existence, during which the child passes from family life to that of school institutions and then to free time. And this may call into question the very nature of education and its meanings. Going to school is considered a necessary condition to get out of "marginality". In fact, that educational opportunities translate for an individual into significant development ultimately depends on whether learning is actually the result of these opportunities, that is, that the latter include useful knowledge, reasoning skills, abilities, values. Cultural heritage must be conceived as an innovative tool to combat certain forms of marginalization and enable the most disadvantaged people to access culture, not only as "public", but as "producers" of it.

It cannot be denied that whoever benefits from the good must know in what it is expressed, even more so today in which the requests that see him involved in different fields of general interest are multiplied; this is because thanks to its "multiplicity" and its "transversality", the asset assumes an importance that goes far beyond the limits given by public cultural institutions and plays a central role in the development of culture by children.

Albert Einstein 1934 had already understood it when, in his volume Comment je vois le monde, published, addressing teachers and students, he asserts that art is the most important of the masters capable of provoking the joy of action creator and knowledge. In his speech he urges the children to reflect well on this aspect:

Chers enfants,

Je me réjouis de vous voir en ce jour devant moi, joyeuse jeunesse d'un pays ensoleillé et béni! Pensez bien à ceci: les choses admirables que vous apprênez à connaître dans vos écoles sont l'oeuvre de nombreuses généra- 
tions, créée dans tous les pays de la terre au prix de grandes peines et d'efforts passionnés. Tout cela est déposé entre vos mains comme un héritage, de manière que vous le racueilliez, que vous le vénériez, que vous le développiez et que vous le transmettiez un jour fidèlement à vos enfants. C'est ainsi que nous, mortels, nous sommes immortels dans cette choses que nous créons en commun, contribuant à des oeuvres impérissables.

Si vous pensez toujours à cela, vous trouverez un sens à la vie et à l'effort et vous acquerrez une juste opinion à l'égard des autres peuples et des autres temps" (p. 3).

\section{Democratization of Culture and Learning of Cultural Heritage}

Culture is also understood as a set of values that give human beings their reason for being and acting, but also as an instrument of democracy, development and cultural expression. This is what was stated on 13 October 2005 in Strasbourg, an occasion on which the representatives of the Ministers of the Council of Europe adopted a Framework Convention on the value of cultural heritage for society, which starts from the idea that knowledge and use of the heritage falls within the citizens' right to participate in cultural life, as specified in the Universal Declaration of Human Rights of 1948. In the text, which bears the title of "Cultural Heritage: the Council of Europe adopts a new convention", heritage is considered a useful source both for human development, for the enhancement of cultural diversity and for the promotion of intercultural dialogue and for the clarification of a model of economic development based on the principles of sustainable use of resources. The Framework Convention, open for signature on the occasion of the Conference of Ministers of Culture and held in Faro, Portugal on 27 and 28 October 2005, at the end of the celebrations for the 50th anniversary of the European Cultural Convention, defined cultural heritage as "a whole of resources inherited from the past that people consider, beyond the regime of property ownership, as a reflection and an expression of their values, beliefs, knowledge and traditions in continuous evolution". This heritage therefore includes all aspects of the environment resulting over time from the interaction between people and places. The same document then recalls the concept of "patrimonial community", which is made up of people who link values to specific aspects of heritage which imply, in the framework of public action, the maintenance and transmission to future generations.

This Convention highlighted the need to place the person and human values at the center of a broader concept of cultural heritage, which sees the latter, if "culturally well managed", as an important resource for improving the quality of life in a society in constant evolution. A heritage that is able to increase educational opportunities and adequately enhance training, that is, capable of affecting "human capital", which is given by the set of knowledge, skills, competences and prerogatives of the people who facilitate the creation of individual, social and 
economic well-being. Human capital is therefore a crucial element for human development, but it is also an invisible capital, the evolution of which is linked to processes with multiple pedagogical, social and psychological implications that significantly influence the growth of children and adults. However, it is also the most difficult asset to administer. The infinite variety and unpredictability of human beings makes it much more complicated to make general assessments of them, compared to what happens with other components or in other areas of life. From this speech emerges an image of education as a complex "whole" (intertwining of affective, cognitive, relational, motivational, action, contextual components), dynamic (in transformation) and integrated (provides for interrelation, interdependence between the parties) in which the different functions occur continuously, specifying. This is the reason why in this respect the problem of the right of children to the use of cultural heritage requires to be treated with extreme caution, even if in any case it cannot be separated from the question of widening access to culture.

This immediately recalls the expression "democratization of culture" which refers to two different meanings: the first linked to the diffusion of education and the second to the equality of opportunities. But global data show that these two realities are extremely contrasted. Although the considerable expansion of schooling produced in Italy in the twentieth century has gradually changed educational institutions, inequalities are still present in terms of gender, social origin, etc. It therefore appears that the expansion of access has not had a considerable effect on the equality of opportunities. A right, the latter, both disregarded and violated. On the other hand, school inequalities are very close, I would say rather in close relation, to the inequalities that occur in the field of the use of cultural heritage. Indeed, to better clarify this concept, we can say that the history of fruition seems to have had a development similar to that of education. At the moment one has the impression of seeing more intense massification, in terms of school participation and enjoyment of the cultural heritage, rather than a real democratization of them since there is still a lack of the same opportunities for access and success at the level social and geographical.

However, if this tells us that the pressure on the "school of the new layers of population has blown up a balance consolidated by tradition, that which was based on the existence of a substantial socio-cultural homogeneity between teachers and students", as well as between users and non-users, we cannot help but underline that selectivity, which in some way, under different forms, still persists at school level and which has remained at the level of use of cultural heritage, shows that the correlation continues to be strong between socio-cultural origin and attendance at high levels of education, and between socio-cultural origin of visitors and customary use. If it is true, therefore, that the picture of the population is changing, it is equally true that the process appears slow and sometimes governed by a "reproductive" logic, making it difficult to ascertain the structural changes that occurred within the processes of schooling and en- 
joyment.

Moreover, as we can see from the numerous researches carried out in the scientific field, the inequality in the quality of use continues to persist, which still today sees many people deprived of the possibility of access to the interpretative tools of cultural heritage. In other words, if literacy and the prolongation of the time of school education are mostly characterized in a democratic sense, the current tendency to manifest the incapacity to ensure the profound internalization of the necessary equipment to take advantage of the opposite meaning of cultural heritage.

This inequality has very considerable effects on the history of individuals, as culture is a necessary condition for democracy and active citizenship. Therefore, it is appropriate to democratize cultural heritage by fighting the exclusion and exile of some areas of culture so that coherence between different cultural actions is ensured. The reasons for this exclusion must also be sought in attitudes and practices of fruition, school and otherwise, which involve a disaffection towards the cultural good (for example, exhausting guided tours where most people cannot fully understand what has been observed and which they have no cognitive or emotional consequences). All children have the right to "know" and "experience" the cultural heritage of their own and other countries, but to do this they need organized and articulated information that regards the life around them and that refers to educational objectives that only the school can and must set.

If one of the tasks of the latter is to offer individuals the chances to be able to rise socially and live in a better way, heritage education can help provide the necessary tools to achieve these objectives and to combat social exclusion (one of the major innovations brought about by the Europe 2020 strategy, adopted in 2010).

Therefore, despite the evident successes in terms of school democratization, in which there is an elevation of the general level of education, inequalities persist still in terms of success and school success, as well as of dependence on access from the environment of origin.

In fact, it is known that the aspirations of families still reproduce the social stratification found in the different types of school, that is, the division into generally non-equal groups that takes place within almost all societies, with an emphasis on the system of inequalities. structural present. It is not surprising then that the positioning of an individual towards other subjects within an organized community determines that the quality of use is better in the case of those who come from more advantageous socio-cultural conditions. In fact, there are "facilitating conditions", ie those environmental factors that facilitate the acquisition and implementation of certain fruition behaviors, which are very complex and therefore must be related not only with the attitude, but also with other variables such as the social action, individual expectations, the value attributed to these results and so on (Fishbein, 1966; Fishbein \& Ajzen, 1974: pp. 59-74).

This also means that the school is not "omnipotent" and that, even if it tries to 
fight against social, gender and cultural inequalities, as recalled by Marie Duru-Bellat (2002), it often ends up being the expression of a society where inequalities remain departing and arriving. School inequalities, as well as fruition inequalities, take root very early and are largely dependent on material and cultural inequalities between families. In this way it happens that children from more disadvantaged backgrounds, children with more difficulties or who come out "less prepared" from the school system, are also those who will probably enjoy less of the cultural heritage.

As is known in learning, the subject is an actor who is going to modify, adapt his responses according to his previous experiences. We speak of learning when punctual behavior tends to reproduce and become habitual behavior. In fact, children face cultural fruition with what are called "prerequisites", that is, the instrumental and cognitive skills that are considered preparatory to the different learning tasks that are proposed to them and that are actually unequal according to the different cultural background possessed by each. It is then clear that a positive attitude towards fruition can only arise when the repetition of those typical behaviors of continuous fruition is determined.

Currently, says Pierre Bourdieu (Bourdieu \& Passeron, 1970: p. 19), the school not only does not seem to be able to correct social inequalities, but also appears to contribute to ensuring its reproduction, as it is dominated by pedagogical actions imbued with a substantial "symbolic violence" and expression of an arbitrary culture.

By treating, as a principle, pupils as if they were equal, it legitimizes social inequalities by transforming them into school inequalities. This phenomenon determines a sort of "amplification" of the differences involving other social and cultural spheres, such as that of the fruition and cultural consumption. In fact, the latter still seems driven by the need for the accumulation of cultural capital and the pursuit of a "profit of distinction" (Bourdieu, 1983: p. 237). This is because in modern societies, in the author's opinion, there are two distinctive systems of social hierarchy: the first, the economic one, in which position and power are determined by wealth and property, and the second, the cultural or symbolic one, in which status is determined by the amount of cultural and symbolic capital owned by individuals. Precisely for this reason, on an exquisitely artistic level, Bourdieu (1983) argues for example that "taste" is an acquired "cultural competence", which has the function of legitimizing social differences and therefore constitutes the "habitus" of the ruling class, which instead recognizes as natural "gift", intelligence, talent. If taste is made to depend on personal characteristics, the only factor regulating the fruition processes is social conditioning. It is not difficult to see that this brings with it a sort of determinism, which consists precisely in the fact that the values that identify the level of personal characteristics have a predictive function of the level of results that each will achieve.

Culture and education are therefore central dimensions in affirming the differences between social classes and in reproducing these differences. 
It is clear, then, that an education without education is not able to ensure the functionality of individual behavior to the assumption of social roles, at least if by education we mean the complex repertoire of attitudes, values, behaviors through which this behavior is specified. Education, as a new value, therefore, serves to bring individuals out of margin and to redesign a new way of doing and thinking about education.

The conditions of quality, equity and efficacy of education constitute an essential factor for the achievement of the objectives of "fundamental education". Consequently, special care must be dedicated to the use of heritage within the school, as in fact this heritage implements a new strategy of cultural discrimination if education does not provide the skills capable of qualifying the profile of individuals, if not characterizes as a moment of construction of freedoms, identity and cultural rights. In this perspective, heritage can help to better respond to the needs, interests and real problems of those who learn by making the learning paths more relevant to the experiences lived by the students. It is like saying that the "good", responding to concrete needs, which often vary considerably from one context to another, from one school to another, from one group to another, from one class to another, etc. that the teaching content can be widely adapted to the specific needs of each.

However, even if there has been recognition of the social and learning value of heritage from many sides, there is still a partial, disordered and discontinuous use of it, as the cultural dimension of social exclusion shows. The right to culture is in fact, at all levels, little mentioned and is configured as a more functional principle for expanding the area of social subordination. Having said this, we must not forget that there are other universal needs and common concerns that must not be forgotten in the curricula and educational messages of which the good is the vehicle: the right of children to know and grow without prejudice, to be active subjects of rights and not of protection. Heritage makes it possible to re-plan the future, and the future for children, which presupposes the need to rethink the ways in which the relationship between the individual and the community has come about (local, national, European and worldwide).

It is a relationship in constant transformation but capable of creating conditions that prefigure new scenarios for learning. The experience of the good is valid and fertile insofar as it leads to perceiving the connections, the meanings, between the different activities of the subject and the resulting consequences. The mere experience of the good, even if suggestive, itself does not enrich the interpretative heritage of individuals. Instead, it must be transformed into its qualitative elements through educational interventions aimed at continually reorganizing and reformulating it. Giving up a conscious and learning-based fruition means applauding an image of culture that has gradually faded and defined by the simple inclusion of large portions of the population.

\section{Cultural Heritage and Active Citizenship}

The school is a place of culture and culture is a source of explicit knowledge and 
learning. In its various articulations and specifications, it constitutes the most direct and institutionalized form of training. And it is for this reason that it is also the only one capable of conferring cultural characteristics on a certain population starting from the reference culture, which defines the degree of appropriation and assimilation of the overall heritage by the individual. It is interesting to note that "education" and "culture" "reveal a continuous and complex specularity: they belong to the entire human species, to the point of almost constructing their distinctive feature. But the continuous differentiation between cultures immediately refers to the differentiation of educational techniques, which is evident both in the transmission and in the learning processes" (Callari Galli, 1995: p. 83).

On the other hand, the values of education and culture that are decisive for man, such as those of responsibility and personal and social commitment, openness to others, active participation in the process of finding self-realization and so on. Obviously all this has a concrete response in the daily educational reality, also and above all at school, since we know that it is in the experience, made by the child since the first years of life, that his future as an adult is played.

The participation of the individual in the social consciousness of the species begins "begins unconsciously almost at birth, and is continually shaping the individual's powers, saturating his consciousness, forming his habits, training his ideas, and arousing his feelings and emotions. Through this unconscious education the individual gradually comes to share in the intellectual and moral resources which humanity has succeeded in getting together. He becomes an inheritor of the funded capital of civilization" (Dewey, 1897: p. 77).

Also the individual's inability to enjoy culture arises during his childhood as a consequence of the education and interventions to which he has been exposed. This is why the entire path that leads to the custom of enjoying cultural heritage must be realized as a continuous process of de-conditioning from that "cultural conformism" (appreciation of dominant and traditionally accepted cultural contents and forms, in terms of aesthetic, moral values etc.) which, resulting from a lack of knowledge and an inability to understand others, would delay and inhibit such development.

Formal education cannot fail to take account of this general process, but we believe that it is necessary to abandon conformism in favor of that "cultural freedom" which, distinguishing itself "from conservation", appears to us as a dynamic concept that evolves with cultural exchange, contrary to the inheritance which refers only to transmission. Founding the learning of the "good" on the relationship between cultural freedom and democracy can serve to accustom the child to seek, discover, invent the elements of culture rather than passively undergo them. In this sense, it seems appropriate to try to identify in the dialectical encounter between education and culture more convincing pedagogical models capable of making the different types of "goods" more accessible to children.

From what has been explained so far, it can be deduced that if it is true that art and culture increase the personal and emotional development of the child, they create social cohesion and provide the creative qualities necessary in a 
modern knowledge-based society, it follows that the school, with its consciously and intentionally pedagogical interventions, must be able to offer all children cultural programs and proposals relating to the heritage without rigid cultural schemes.

Being promoters of the right to culture does not mean, therefore, only erecting champions of the right to go to school but above all of the effective appropriation of the knowledge that has meaning, which cannot be considered simply information to be taken on, but knowledge, skills and competences that serve to face reality and to interpret it. It is the right to intellectual activity, to expression, to imagination, to the understanding of natural and social aspects, it is the right to find and select that information which allows to build relationships with the world, with others and with oneself themselves. It must be recognized that didactic and pedagogical actions are often far from guaranteeing these rights and starting a real transformation in this direction.

Instead, we are faced with an education that is still conceived as an accumulation of knowledge rather than as a process of valorization and construction of knowledge and as the "capital" of an evaluable investment.

The growth of the school is linked to positive expectations in terms of the overall structure of the company, the improvement of living conditions, in the most general sense, but also of the aspects that concern the use. However, it must be said that a new idea of school necessarily implies an expansion of the catalogs of training content and moves towards a perspective of progress by assigning a central role to heritage in the construction of the cultural repertoires of individuals and collectives. In doing this, however, the school must be able to develop training proposals that ensure a certain functionality to the acquisitions and identify in them dynamic components capable of replacing mobility in cultural consumption with a more relevant and authentic fruition based on precise and determined objectives of competence.

These findings lead us to define competence as knowing how to act based on the mobilization and effective use of a set of resources, which can take different forms, personal and internal (motivation, particular attitudes, interests, prior knowledge, experiences and so on via) and external and bearers of a cultural dimension (material and technical, human and environmental), which inevitably bring students into contact with significant cultural objects in an exploration that will allow them to progress in the development of the competence itself.

In light of what has been said here, it becomes crucial creating strong skills in the user, which help to face and manage the different dimensions of culture. It is skills that can only originate from an education capable of strengthening the child from the point of view of learning and his basic tools, which ensure effective and concrete possession. It can be understood from here how "literatism", at different levels, allowing to come at a truly capable education to give back the word to those who have been deprived of it in the past and present. This link education-cultural heritage also allows us to affirm that individuals, children are not all equal neither from the socio-cultural point of view nor from the heredi- 
tary one. However, if it is true that it is not possible to intervene on the hereditary characteristics, we can do it instead by acting on the environment through education is the only way to overcome these inequalities. The learning of the cultural asset must therefore necessarily go through a meaningful learning, which is considered "personally" significant for the pupil when it allows him to make links with what he knows and with the questions he poses and "socially" significant when it offers him the tools to better understand the social, cultural and physical reality of which he is a part. Learning tool and means for building the network of relationships between the different meanings of which culture is the bearer, the cultural asset requires to be interdisciplinary and transversal skills capable of guaranteeing unity and quality in the use and essential for the development of capacity in children to penetrate the different souls of culture, which has ties with the local, national, international and world community.

In a sense of cultural rights, learning is attributable to:

- survival skills: learning to live;

- individual and social skills: learning to be;

- learning skills: learning to learn.

Of the three, it is essential to recall "learning competence" which allows you to reinvest the acquired acquisitions in experience, that is, the competence that allows you to learn progressively to manage your learning. Knowing how to learn requires that individuals know how to define their learning objectives, evaluate the relevance of their choices and strategies, manage their own times. This allows to evolve practices in the most appropriate ways and what a person can do. Changes in attitudes occur over a long period of time and need to be felt. This explains above all the constant interferences between training, family and social life, interferences which in the case of fruition become stronger. It can be thought, for example, that there are certain correlations between an individual's ability to manage their cultural consumption and learning in the school field.

Among the pedagogical procedures capable of facilitating these transformations in the context of attitudes to the use of genuine interest are the tools used to foster the awareness of the learner, awareness based on the observation and critical analysis of experiences of cultural consumption, as well as those of non-consumption. The complementary observation that can be made is that conducting an in-depth reflection on one's own experience of "cultural consumption" is given by the possession of strong interpretative tools and does not fall within the natural behaviors of the learner. The repertoire of key competences and the ability to learn must therefore be built.

You learn to learn, to use, to experience, to love and to have respect for the cultural good just as you learn to be an active member of society, to take on personal, political, cultural and economic responsibilities (educate children, vote, pay taxes etc.), to participate in cultural life and to promote the objectives of a democratic society. Active citizenship was set as a cross-cutting objective of all school teaching in the Lisbon agreements (2000) to develop a knowledge society. Cultural heritage can be a strong ally in the construction of "educational citi- 
zenship", which implies an education understood as learning "of", "for" and "in" democracy and which also becomes a "culture of rights and responsibility". "Educational citizenship" can take active and passive forms. In fact, there are many essential aspects and responsibilities that concern the active use of heritage in a democratic sense, for example participation, information management, tolerance for other cultures and tolerance for other opinions and cultures.

Heritage is an important resource to create stimulating learning environments, to help people build their identities, to support the change of inequalities in cultural equality, to broaden the concept of productivity to cultural creativity, to bring local realities into contact with other transnational realities promoting dialogue, in summary to make knowledge accessible to all individuals. It can be called "the sounding board of collective memory and therefore of our collective biography".

That the good represents a privileged way to access culture was well understood by the European community when in an international conference, "A Muste or a-Muse”, held in Rotterdam, the Netherlands from 26 to 29 September 2001 , decided to connected a survey to analyze the limits of their practices on artistic teaching and cultural heritage in Europe. The aim was to improve the cohesion and coordination of educational policies in the heritage field. It is a matter of going to verify the relationship between education and the world of cultural institutions. In an attempt to focus on these problems, attention was focused on the conference mentioned

- cultural legitimacy of educational policy;

- cultural education in practice;

- effects of cultural education.

Some key aspects of the change were also identified:

- how to break down the barriers between school and culture;

- how to promote cultural educational policies to provide to foster cultural culture by combining an effective sense of identity and respect for diversity;

- how to organize curricula capable of supporting cultural education;

- how to promote citizenship both at national and European level.

Three years later, from 8 to 10 September 2004 in La Haye in the Netherlands, another conference was organized entitled "La culture et l'école: Politiques d'enseignement Artistique et du Patrimoine au sein de l'Unioneuropéenne" "Culture and School: Policies for Arts and Heritage Education across the European Union”, during which data relating to research conducted in twenty-nine European countries was made public. In the report, prepared by the Netherlands Ministry of Education, Culture and Science, an attempt was made to highlight what was elaborated by the various countries of the European Union on subject of curricula concerning heritage. These operations, in addition to helping to identify comparable indicators relating to artistic and heritage teaching and the relationship between arts and education, have served to affirm the importance of cultural heritage, which plays a crucial role in education by helping to build the European citizenship and to improve mutual understanding between citizens. 
Thus, it was argued that heritage education and European citizenship make democracy work for Europe.

As history has taught us, citizens must be formed educated to feel responsible for a community to which they belong and which protects their life and rights. This is the reason why some principles underlie the understanding of history and cultural heritage especially when examining the objectives and strategies of a childhood culture:

- democracy (for all);

- proximity (about children's daily habits);

- quality of experiences.

Already for Aristotle, polis and paideia, the political community and education, were two sides of the same coin, a territory of free citizens, in which everything related to education, the education of newcomers coincided with the civic training of citizens in terms of democratic coexistence. We are faced with a universal and unitary vision of culture that pushes education to transcend borders and that promises a memory and a destiny common to all humanity. Culture therefore seems to be a dimension with a universal rather than a particularistic vocation and this idea appears common to society and school; although it is quite clear that "scholastic knowledge" to be meaningful for pupils must at the same time be bearers of the history of humanity (knowledge responds to the questions that man has placed on others and on the world) and an expression of belonging culture (some knowledge is universal, others specific to contexts within the community).

International research (van Dijk \& van Zuijlen, 2002) have attempted to study the real cultural participation of students, the interaction between cultural groups, or how the different arts develop people's norms and values, and especially for what reason the different partners establish collaborations between cultural institutions in order to improve social cohesion. At other levels, efforts were then made to understand how to monitor and evaluate implementation policies and measure the cultural effects of heritage on life.

These studies concern educational equity, inclusion and exclusion, empowerment, socialization, conflict resolution, identification of particular types of training, cultural aspects of communities, intercultural and cross-cultural understanding, human rights education, citizenship education, multi and intercultural education, educational heritage, educational, social and personal values, adult education, the educational community and learning for the whole life, intergenerational learning, the development of self-esteem, cognitive and artistic skills and creativity, but they also extend to research relating to material culture, cultural transmission, globalization, ethnicity and relevant cultural changes. The international research have attempted to study the real cultural participation of students, the interaction between cultural groups, or how the different arts develop people's norms and values, and especially for what reason the different partners establish collaborations between cultural institutions in order to improve social cohesion (Nuzzaci, 2015). At other levels, efforts were then made to 
understand how to monitor and evaluate implementation policies and measure the cultural effects of heritage on life.

It is a reflection on cultural capital that has manifested itself predominantly within the European community, which, in the desire to build a European cultural space, has shown a lot of attention to the educational value of the heritages (artistic, demo-ethno-anthropological etc.) and to its educational value. Think of the different Socrates programs, such as, for example, the Comenius program on the evaluation of the portfolio in the visual arts or the one concerning teacher training programs, from kindergarten to kindergarten and primary school. Supporting the European dimension of school heritage, or rather expanding European knowledge and exchanging programs between teachers, then means offering a substantial contribution to the educational value that the cultural asset assumes in providing full personal citizenship to all individuals and take care of social awareness (Chapman, 1978: p. 19) (Figure 2 \& Figure 3).

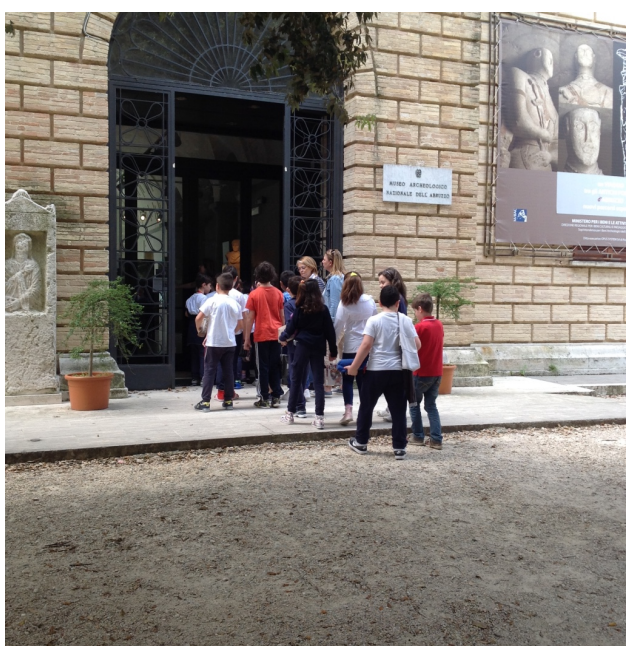

Figure 2. Entrance to the National Archaeological Museum of Villa Frigerj (Chieti).

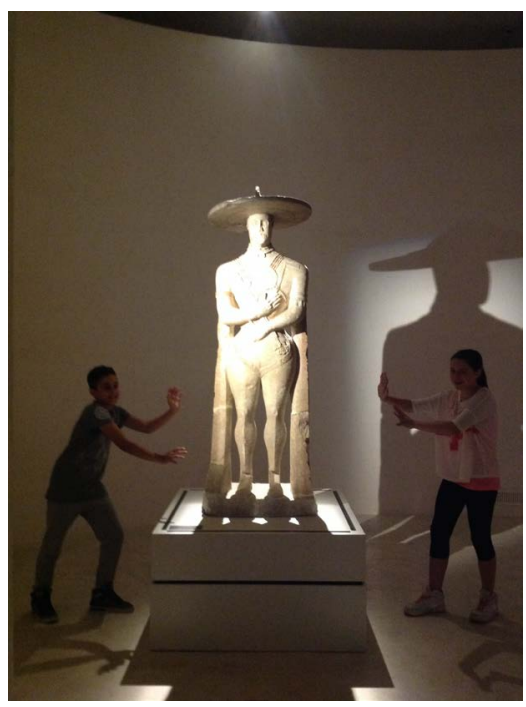

Figure 3. The Warrion of Capestrano. 
The hypothesis that cultural heritage plays a crucial role in the development of European citizenship seems confirmed by the fact that it has an important social function by ensuring the continuity of man's adaptive process to the environment and by transferring the repertoires of knowledge to subsequent generations. It should be noted how this process helps to define not only diversity and commonalities, but above all to take note of the plurality of life, which range from homogenization and uniformity to multiplicity and multi-identity or multi-citizenship. Cultural heritage contains in a nutshell the key concepts of citizenship (rights, participation, cultural pluralism and identity) and assume an educational role of increasing importance, as they help diversities to negotiate and multiple identities to relate to others. This constitutes the conditio sine qua non of social cohesion. Surely, therefore, cultural heritage affirms respect for differences, allows you to explore plurality and promote the development of the independence of the mind, in other words, it is able to affect man and society. Society is increasingly pushing towards forms of integrated coexistence that broaden the concept of citizenship by forcing education to change, that keep the dynamics of the future in mind. All human education, as August Comte had said, must prepare everyone to live for others, so that they can relive themselves in others.

The richness of the themes that revolve around that of citizenship and citizen is captured with the classic definition reported by the English sociologist Thomas Humphrey Marshall (1950): "citizenship is a status that is given to those who are full members of a community [...] requires [...] a direct perception of belonging to the community, belonging based on loyalty to a civilization that is common possession. It is a loyalty of free men, provided with rights and protected by a common law. Its growth is stimulated, both by the struggle to obtain these rights, and by their enjoyment once obtained" (1950: pp. 24-34).

The idea of European citizenship can be conceptualized by establishing which skills are needed by citizens and which could give a contribution to the education of the arts and cultural heritage. Citizenship gives development to cultural identity but has a duty to respect other identities. Central aspects of this discourse are therefore to be considered the key skills that serve to make the individual competent, reflective, active, responsible, widely participatory of multicultural values and of one's own identity (multiple identities). With respect to the contribution of cultural heritage to the development of citizenship, it is necessary to ask which kind of citizen you want to promote with heritage education. The answer to this question must, in my opinion, start precisely from the analysis of the meanings of heritage and education, even if the literature already shows us three prevailing aspects of "good citizen": personally responsible, participatory and oriented towards justice.

From here it is important to assume that the good allows us to teach the meaning of democracy (Parker, 1996) and to explore its "strong" or "advancement" aspects that increase the "clothes of the mind". Linking the concept of 
good to that of democracy in learning activities helps to make information more factual and increases students' awareness of the need to become future citizens "democratically strong" rather than "democratic spectators".

It is a "cultural capital" that enriches the territory not only because it increases its attractiveness and identity, but also because its development is able to retain intellectual capital (talented people who want to continue living and work in that area because they find it stimulating and culturally rich) and to fertilize "social capital", that is, the trust underlying economic development. Precisely for these reasons, we believe that exercising the right to fruition can help children not to be discriminated against in any way in language, religion, ethnicity, social origin, thought, disability and so on, and that it gives their chance to be heard. This is because there is no longer "a culture that consoles in suffering, but a culture that protects from suffering, that fights and eliminates them (Vittorini, 1945), to come to see, as Comenius had said well, that all men have the right to that "deeply rooted comprehensive instruction on things, which should make them individuals capable of speaking a common language which can put them all in direct contact with each other (Comenio, 1992/1668).

\section{Conclusion}

The findings of this study have exposed the role played by the use of cultural goods in the field of education. There is sufficient evidence showing how the fruition of the cultural heritage is able to influence the cultural profiles of individuals, in terms of key competences to be acquired in order to exercise active citizenship.

The "omnibus, omnia omnino" (everything to everyone) of Jan Amos Komensky (Comenio, 1993/1657) is valid for all men, as for children, women, adolescents, the elderly, as the universality of education concerns at the same time, the whole human race and all human knowledge and know-how and to achieve it, therefore requires a "not flashy but true" culture, of all and for all, which passes through "a new citizenship", right, as Victor Hugo claimed, from that utopia of today which is the reality of tomorrow. In short, a culture in the historical continuity of cultural heritage lays the foundations of the future and translates into education for humanity.

\section{Limitations to the Study}

One of the limitations of the study concerns the fact that there are numerous variables that come into play in the affirmation of the right to the use of cultural heritage as a cultural right, especially with reference to educational processes. In this contribution, some variables were not sufficiently enlightened due to the breadth and complexity of the problem addressed. This did not make it possible to sufficiently appreciate the complexity of the entire previous research work conducted by the author. The theoretical dissertation has in fact privileged the examination of some macro-variables over others, which can be considered ac- 
cording to specific dimensions.

In perspective, we will turn to study empirically methods and tools to ensure quality cultural use in educational contexts to raise the cultural profiles of the school population.

\section{Conflicts of Interest}

The author declares no conflicts of interest regarding the publication of this paper.

\section{References}

Arendt, H. (2001). La crisi dell'istruzione. Tra passato e futuro (1961). Milano: Garzanti. Bourdieu, P. (1983). La distinzione: Critica sociale del gusto. Bologna: Il Mulino.

Bourdieu, P., \& Passeron, J. C. (1970). La reproduction. Eléments pour unethéorie du systèmed'enseignement. Paris: Minuit.

Bruner, J. (1988). La mente a più dimensioni. Bari: Laterza.

Callari Galli, M. (1995). Educazione, cultura, scuola. In B. Vertecchi (Ed.), Il secolo della scuola. Educazione del Novecento. Firenze: La Nuova Italia.

Chapman, L. H. (1978). Approaches to Art in Education. New York: Harcourt Brace Jovanovich.

Comenio, J. A. (1992). La via della luce. Tirrenia (Pisa): Edizioni del Cerro, Tirrenia.

Comenio, J. A. (1993). Grande didattica (1629-1932/Latin Translation 1657). Firenze: La Nuova Italia.

Dewey, J. (1897). My Pedagogic Creed. The School Journal, 54, 77-80.

Dewey, J. (1961). Come Pensiamo. Firenze: La Nuova Italia.

Dewey, J. (2000). Democrazia e educazione (1916). Firenze: La Nuova Italia.

Duru-Bellat, M. (2002). Lesinégalitéssociales à l'école. Paris: PUF. https://doi.org/10.3917/puf.duru.2002.01

Einstein, A. (1934). Comment je vois le monde. Paris: Flammarion.

European Commission (2018). Learning from the past, designing our future: Europe's cultural heritage through eTwinning. Brussell: Central Support Service for eTwinning

Fishbein, M. (1966). The Relationship between Beliefs, Attitudes, and Behaviour. In S. Feldman (Ed.), Cognitive Consistency (pp. 199-223). New York: Academic Press. https://doi.org/10.1016/B978-1-4832-2828-0.50012-X

Fishbein, M., \& Ajzen, I. (1974). Attitudes toward Objects as Predictors of Single and Multiple Behavioural Criteria. Psychological Review, 81, 59-74. https://doi.org/10.1037/h0035872

Galisson, R., \& Puren, C. (1999). La formation en questions. Paris: Clé International.

Herskovitz, M. J. (1948). Man and His Work: Works: the Science of Cultural Anthropology. New York: Alfred A. Knopf.

Kluckonhn, C. (1960). Mirror for Man. New York: McGraw-Hill Book Company.

Levi-Strauss, C. (1980). L'identità. Palermo: Sellerio.

Marshall, T. H. (1950). Cittadinanza e classe sociale. Torino: UTET.

Mead, G. H. (1966). Mente, sé e società (1934). Firenze: Giunti Barbera.

Meirieu, F. (2002). Le pédagogue et les droits de l'enfant: histoire d'un malentendu? Paris: 
Editionsdu Tri. https://doi.org/10.3917/jdj.214.0026

Milani, L. (1965). L'obbedienza non è più una virtù. Firenze: Libreria Editrice Fiorentina.

Nuzzaci, A. (2001). Musei, educazione, apprendimento: Una ricerca sperimentale nel settore demoetnoantropologico. Roma: Kappa.

Nuzzaci, A. (2004a). Ricerca sperimentale e didattica museale: Due studi a confronto. In M. R. Iacono, \& F. Furia (Eds.), Educazione al patrimonio culturale: Problemi di formazione e di metodo. Atti del Convegno (pp. 189-203). Caserta: Arethusa.

Nuzzaci, A. (2004b). Esposizioni temporanee e collezioni permanenti. Un'analisi comparata dei pubblici per migliorare la qualità della proposta didattica. In E. Nardi (a cura di), Musei e pubblico. Un rapporto educativo (pp. 35-60). Milano: FrancoAngeli.

Nuzzaci, A. (2007). Il diritto del bambino di fruire del patrimonio culturale. In A. Bobbio (a cura di), I diritti sottili del bambino (pp. 129-163/164). Roma: Armando.

Nuzzaci, A. (2015). University, School, Territory: Strategies and Activities of Inter-Institutional Partnerships of the Degree Course in Sciences of Primary Education. In P. Blessinger \& B. Cozza, (Eds.), University Partnerships for Community and School System Development (Vol. 5, pp. 233-258). Bingley: Emerald Group Publishing. https://doi.org/10.1108/S2055-364120150000005013

Nuzzaci, A. (2016). I beni culturali tra competenze, identità e atteggiamento verso la fruizione: il ruolo della ricerca educativa. In T. Aja, L. Calandra, \& A. Vaccarelli (a cura di), L'educazione outdoor: Territorio, cittadinanza, identità plurali fuori dalle aule scolastiche (pp. 178-193). Lecce-Brescia: Pensa MultiMedia Editore s.r.l.

Nuzzaci, A. (2017). ICT, beni culturali e formazione iniziale e in servizio degli insegnanti: il progetto "Il Museo in...Click!". In P. Limone, \& D. Parmigiani (a cura di), 'L'educazione digitale'-Modelli pedagogici e pratiche didattiche per la formazione iniziale e in servizio degli insegnanti (pp. 258-271). Bari: Progedit.

Parascandolo, R. (1997). Opinione pubblica e opinione di massa. In J. Jacobelli (Ed.), Scienza e informazione (pp. 161-168). Bari: Laterza.

Parker, W. C. (1996). “Advanced” Ideas about Democracy: Toward a Pluralist Conception of Citizen Education. Teachers College Record, 98, 104-125.

Pontecorvo, C., Ajello, A. M., \& Zucchermaglio, C. (1995). I contesti sociali dell'apprendimento. Acquisire conoscenze a scuola, nel lavoro, nella vita quotidiana. Milano: LED.

Sandell, R. (1998). Museums as Agents of Social Inclusion. Museum Management and Curatorship, 17, 401-418. https://doi.org/10.1080/09647779800401704

Schmidt, H. (2000). Globalizzazione. Sfide politiche, economiche e culturali. Roma: Lavoro.

UNESCO (1949). Fondamental Education: A Description and Programme. Paris: UNESCO.

United Nations (1948). Universal Declaration of Human Rights (UDHR). United Nations General Assembly.

United Nations (1990). World Declaration on Education for All. Jomtien: Thailand.

van Dijk, G., \& van Zuijlen, J. (2002). A Must or a-Muse. Proceedings of Conference Results Arts and Culture in Education: Policy and Practice in Europe. Utrecht: Cultuurnetwerk Nederland.

Vittorini, E. (1945). Una nuova cultura. Il Politecnico. 